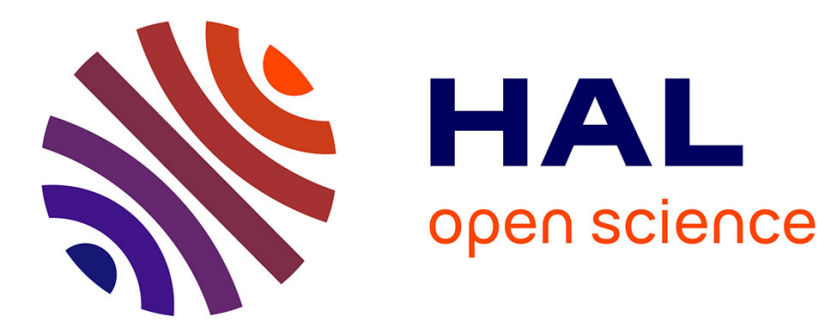

\title{
Effects of inbreeding on population mean performance and observational variances in Eucalyptus globulus
} João Costa E Silva, Craig Hardner, Paul Tilyard, Ana M. Pires, Brad M. Potts

\section{To cite this version:}

João Costa E Silva, Craig Hardner, Paul Tilyard, Ana M. Pires, Brad M. Potts. Effects of inbreeding on population mean performance and observational variances in Eucalyptus globulus. Annals of Forest Science, 2010, 67 (6), 10.1051/forest/2010018 . hal-00883626

\section{HAL Id: hal-00883626 https://hal.science/hal-00883626}

Submitted on 1 Jan 2010

HAL is a multi-disciplinary open access archive for the deposit and dissemination of scientific research documents, whether they are published or not. The documents may come from teaching and research institutions in France or abroad, or from public or private research centers.
L'archive ouverte pluridisciplinaire HAL, est destinée au dépôt et à la diffusion de documents scientifiques de niveau recherche, publiés ou non, émanant des établissements d'enseignement et de recherche français ou étrangers, des laboratoires publics ou privés. 


\title{
Effects of inbreeding on population mean performance and observational variances in Eucalyptus globulus
}

\author{
João Costa E Silva ${ }^{1,2 *}$, Craig Hardner ${ }^{3}$, Paul TILyard $^{4}$, Ana M. Pires $^{2}$, Brad M. Potts $^{4}$ \\ ${ }^{1}$ Centro de Estudos Florestais, Departamento de Engenharia Florestal, Instituto Superior de Agronomia, Universidade Técnica de Lisboa, \\ Tapada da Ajuda, 1349-017 Lisboa Codex, Portugal \\ ${ }^{2}$ Centro de Matemática e Aplicações, Departamento de Matemática, Instituto Superior Técnico, Universidade Técnica de Lisboa, \\ Avenida Rovisco Pais, 1049-001 Lisboa, Portugal \\ ${ }^{3}$ University of Queensland, School of Land, Crop and Food Sciences, St Lucia 4072 Queensland, Australia \\ ${ }^{4}$ School of Plant Science and Cooperative Research Centre for Forestry, University of Tasmania, Private Bag 55, Hobart, Tas. 7001, Australia
}

(Received 1 June 2009; accepted 21 December 2009)

Keywords:

Eucalyptus globulus / self-fertilization /

mixed mating /

inbreeding depression /

outcrossing rate /

REML variance components

\begin{abstract}
- Mean performance and variances were studied in self (SELF), open pollinated (OP) and unrelated polymix (POL) crosses of common parentage in Eucalyptus globulus.

- Inbreeding depression for survival (SURV) and basal area per hectare (BAH) was the highest reported for a SELF eucalypt population, increasing with age to reach 74 and $77 \%$, respectively, over 10 years.

- Inbreeding depression in the OP was 36\% for SURV and 32\% for BAH at age 10 years, and estimates of outcrossing rate from BAH were stable across ages, averaging 0.56. In contrast, OP inbreeding depression for stem diameter (DBH) of survivors decreased with age and few selfs appeared to survive to 10 years.

- There was more variation in DBH between and within SELF than POL families, with variance ratios consistent with rare and partially recessive deleterious alleles causing inbreeding depression.

- The OP variances were initially more similar to the SELF population but converged to the POL population after 10 years.

- It is argued that when outcrossing rates are low, as in the present case, inbreeding depression will be a significant force countering local adaptation in forest trees.
\end{abstract}

\section{INTRODUCTION}

The response to artificial or natural selection on quantitative traits is normally predicted assuming random mating and simple additive genetic models (Lynch and Walsh, 1998). However, mixed mating is common in many plant species where, under open pollination, progenies may contain a mixture of selfs and unrelated outcrosses (Goodwillie et al., 2005; Vogler and Kalisz, 2001). Understanding the evolution of mixed mating systems and response to selection under mixed mating thus requires a better knowledge of the quantitative genetic architecture of open-pollinated populations (Lande and Schemske, 1985). Two key factors driving the quantitative genetic architecture and performance of open-pollinated progeny are the levels and genetic consequences of inbreeding. The ready application of allozymes and molecular markers to mating system analysis means that there is a reasonably good understanding of the levels and variation in outcrossing rates in many plant genera (Byrne, 2008; Goodwillie et al., 2005; Potts et al.,

*Corresponding author: jces@isa.utl.pt
2008). However, the consequences of inbreeding on population means and variances are less well studied (Kelly, 2005).

A common response of both plants and animals to inbreeding is a decline in mean performance, which is usually termed inbreeding depression (Lynch and Walsh, 1998). Inbreeding depression is commonly observed in fitness related traits associated with survival, reproduction and growth, and is believed to arise through two main non-mutually exclusive mechanisms: firstly dominance, whereby inbreeding unmasks deleterious recessive or partially recessive alleles; and secondly, whereby inbreeding increases homozygosity at loci exhibiting overdominance (Charlesworth and Charlesworth, 1987; Lande and Schemske, 1985). From an evolutionary and conservation perspective, inbreeding depression is important as it will initially lower population fitness, resulting in a phase where small populations of normally outbred species are more susceptible to ecological or genetic displacement (Ellstrand and Elam, 1993; Lopez et al., 2000). However, such selection may eventually result in the purging of deleterious alleles from populations surviving bottlenecks (Klekowski, 1988). The distribution of genetic variation among and within families is also expected to differ under inbreeding compared with non-inbred 
populations (Cockerham and Weir, 1984; Moorad and Wade, 2005). Consistent with theoretical expectations, populations derived from the inbreeding (mainly selfing) of predominantly outcrossing species may exhibit greater between- and withinfamily variances than outcrossed populations (Kelly, 2005; Williams and Savolainen, 1996).

Inbreeding depression is commonly observed in forest tree genera (Klekowski, 1988; Sedgley and Griffin, 1989; Williams and Savolainen, 1996). Such genera usually comprise large, long-lived organisms which typically have mixed or outcrossed mating systems (Sedgley and Griffin, 1989). This is certainly the case in the predominantly Australian genus $\mathrm{Eu}$ calyptus where, across the 23 species tested, outcrossing rates in the wild average 74\% (Byrne, 2008; Potts and Wiltshire, 1997). The few eucalypt species studied to date have all shown significant inbreeding depression on traits related to fitness, not only following controlled selfing (Griffin and Cotterill, 1988; Hardner and Potts, 1995; 1997; Hardner and Tibbits, 1998; Hardner et al., 1998; Lopez et al., 2000), but also in offspring derived from open-pollinated seed collected from the wild (see previous citations; Hodge et al., 1996; Volker, 2002). However, the limited number of founder parents used in these studies would limit their power for evaluating the effects of inbreeding, particularly on observational variance components.

Eucalyptus globulus Labill. is native to south-eastern Australia but widely grown in pulpwood plantations throughout temperate regions of the world (Potts et al., 2004). As with most eucalypts (Byrne, 2008), the species is animal pollinated and has a mixed mating system. Average outcrossing rates in dense native forests are above 86\% (Jones, 2005; Mimura et al., 2009), although individual tree outcrossing rates can vary between 0 and $100 \%$ depending largely on the self-incompatibility (Patterson et al., 2004; Potts et al., 2008), canopy position (Patterson et al., 2001; 2004) and the density of trees in the landscape (Mimura et al., 2009). In the present paper, we report 4, 6 and 10-year-old survival and growth results from a field trial established with Eucalyptus globulus families obtained from selfing, open pollination and unrelated polymix crossing of 50 base parents, 28 of which could be successfully self pollinated. This is the largest number of parents yet used to compare populations derived from selfing, outcrossing and natural mixed mating in eucalypts. We here aim to understand the age trends in the effects of inbreeding on population mean performance and on between- and withinfamily variances for both self and open-pollinated populations. We are specifically interested in finding whether inbreeding depression in both the self and open-pollinated populations will have long-term impacts on survival and site productivity and, secondly, how inbreeding impacts on the variability in growth.

\section{MATERIALS AND METHODS}

\subsection{Crossing design}

Fifty one mature trees were randomly selected from the natural $E$. globulus population bordering the D'Entrecasteaux Channel, south of Hobart, as seed parents for this study. This area is in the centre of the large and continuous coastal distribution of E. globulus in southeastern Tasmania, and the seed parents were spread over a $16 \mathrm{~km}$ distance (latitude $43^{\circ} 2^{\prime} 6.54^{\prime \prime} \mathrm{S}$ and longitude $147^{\circ} 20^{\prime} 13.56^{\prime \prime} \mathrm{E}$ to latitude $43^{\circ} 9^{\prime} 13.11^{\prime \prime} \mathrm{S}$ and longitude $\left.147^{\circ} 14^{\prime} 19.59^{\prime \prime} \mathrm{E}\right)$. The trees were generally more than 50-100 $\mathrm{m}$ apart and are assumed to be unrelated (Hardner et al., 1998). They are remnants from various degrees of forest clearing, but were usually in close proximity to many other native E. globulus trees.

The cross types applied to each seed parent were artificial self pollination (SELF), open pollination (OP) and artificial outcrossing with a pollen polymix (POL). The OP seed was collected from each parent tree in two successive years during spring-summer flowering from the mid- to lower canopy (see Patterson et al., 2001). The pollen mixture used under the POL cross type was from two independent samples of 30 mature E. globulus trees from the same natural population as sampled for the seed parents, but unrelated and not neighbouring them. The distribution of seed parents was unbalanced due to crossing failure. In particular, several parents that were represented in the other cross types were missing in the SELF cross. After combining the two OP seed collections into a single cross type, and similarly the two POL samples, the number of seed parents represented by each cross type was 28, 50 and 48 for SELF, OP and POL, respectively. SELF had 27 and 26 seed parents in common with OP and POL, respectively; there were 48 parents in common between OP and POL.

\subsection{Field trial}

A field trial was established with progeny blocked according to pollination treatment to reduce competition effects among progenies from different cross types, as different inbreeding levels were expected to lead to substantial variation in growth rate (Hardner and Potts, 1997). In this sense, pollination treatments comprised 5 main plots ( 1 for the SELF, 2 for each of the OP samples, and 2 for each of the POL treatments) randomized within each of 23 replicates. Progeny from a seed parent within a given cross type was randomly allocated within the respective main plot, and represented by a singletree plot. For a few seed parents, the number of plants from a given pollination treatment was insufficient to allow complete distribution across the 23 replicates, in which case the missing positions within main plots were filled with individuals from other seedlots of the same pollination treatment. Trees were planted at $2.5 \mathrm{~m} \times 3.5 \mathrm{~m}$ spacing.

The trial site was located in West Ridgley, Tasmania (latitude $41^{\circ}$ $10^{\prime} 28^{\prime \prime}$, longitude $145^{\circ} 46^{\prime} 22^{\prime \prime}$ ). The planting site was an ex-pasture area, with a slight to moderate slope and located at an altitude of approximately $280 \mathrm{~m}$. The soil was a clay loam kraznozem, exhibiting little variability over the trial area. Site preparation included rip mounding and pre-planting herbicide treatments.

\subsection{Traits measured}

The trial was assessed at 4, 6 and 10 years from planting. Survival (dead/alive) was recorded for each individual tree, and the proportion of planted trees alive per main plot (SURV) calculated. Over-bark diameter at breast height (DBH) was measured on surviving trees. Basal area was calculated for each tree as $\mathrm{DBH}^{2} \times \pi / 4$, and then the basal area per hectare $(\mathrm{BAH})$ for each main plot was calculated as $[(\mathrm{BA} / \mathrm{Sp})$ 
$\times 10000] \times$ SURV, where BA is the main plot average of individual tree basal areas, Sp is the tree spacing (in $\mathrm{m}^{2}$ ) and SURV is defined as above. Thus, BAH estimates productivity, while accommodating differences between main plots in survival.

\subsection{Data analysis}

The aims of the analyses of SURV and BAH were to estimate and test inbreeding depression and calculate outcrossing rates at the population level. In addition to these objectives, the analysis of $\mathrm{DBH}$ aimed to estimate between- and within-family variances for each cross type. The analyses of the individual traits were undertaken following the general linear mixed model:

$$
\mathbf{y}=\mathbf{X b}+\mathbf{Z}_{\mathbf{0}} \mathbf{u}_{\mathbf{0}}+\mathbf{Z}_{\mathrm{g}} \mathbf{u}_{\mathrm{g}}+\mathbf{e}
$$

where $\mathbf{y}$ is the $N \times 1$ combined vector of observations over cross types for a given trait $\left(N=\sum_{i=1}^{p} N_{i}\right.$, where $N_{i}$ is the number of observations in the $i$ th cross type, $i=1 \ldots p)$, $\mathbf{b}$ is the $l \times 1$ vector of fixed effects with a $N \times l$ incidence matrix $\mathbf{X}, \mathbf{u}_{\mathrm{g}}$ is the $n p \times 1$ vector for the random effects of $n$ female parents in each of $p$ cross types with a $N \times n p$ incidence matrix $\mathbf{Z}_{\mathbf{g}}, \mathbf{u}_{\mathbf{0}}$ is the $m \times 1$ vector of random effects involving experimental design features with a $N \times m$ incidence matrix $\mathbf{Z}_{\mathbf{0}}$, and $\mathbf{e}$ is the $N \times 1$ vector of residual terms for each of $p$ cross types. Initial analysis of DBH indicated that correlations in family (i.e. parental) performance between the two OP seed collections were generally high and not statistically different from one $(P>0.05)$. This was also the case for the two samples of pollen mixture in POL. Thus, the information within OP or POL was pooled into one cross type to simplify the analyses of all traits. Consequently, $p=3$ for the number of cross types. As not all the seed parents were represented in all cross types, $\mathbf{Z}_{\mathrm{g}}$ contained some columns of zeros, enabling the unbalanced nature of the data to be accommodated.

The data vector (y) contained main plot observations at a given age for SURV and BAH, but individual tree measures for DBH. For all traits, the terms in $\mathbf{b}$ included the overall trial mean and the effects associated with cross type. The family effects in $\mathbf{u}_{\mathbf{g}}$ were fitted under the analysis of DBH only. The vector $\mathbf{u}_{\mathbf{0}}$ had a sub-vector of replicate effects in the analyses of all traits. For DBH, additional sub-vectors in $\mathbf{u}_{\mathbf{0}}$ comprised effects due to the interaction between replicates and cross types, and the interaction between replicates and families; for the later effects, separate interaction terms were fitted for different cross types (i.e. for OP and POL only, as for SELF there was only one tree per family within each replicate). In the analyses of SURV and $\mathrm{BAH}$, the interaction between replicates and cross types could also be included in $\mathbf{u}_{\mathbf{0}}$, but with the incidence matrix specified to fit the interaction effects using data from OP and POL only (as there was only one main plot observation in each replicate for SELF).

Under model (1), the joint distribution of the random terms was assumed to be multivariate normal, with the mean vector and variance matrix defined as:

$$
\left[\begin{array}{l}
\mathbf{u}_{\mathbf{0}} \\
\mathbf{u}_{\mathrm{g}} \\
\mathbf{e}
\end{array}\right] \sim N\left(\left[\begin{array}{l}
\mathbf{0} \\
\mathbf{0} \\
\mathbf{0}
\end{array}\right], \quad\left[\begin{array}{lll}
\mathbf{G}_{\mathbf{0}} & \mathbf{0} & \mathbf{0} \\
\mathbf{0} & \mathbf{G}_{\mathbf{g}} & \mathbf{0} \\
\mathbf{0} & \mathbf{0} & \mathbf{R}
\end{array}\right]\right)
$$

where $\mathbf{G}_{\mathbf{0}}, \mathbf{G}_{\mathbf{g}}$ and $\mathbf{R}$ are variance matrices pertaining to $\mathbf{u}_{\mathbf{0}}, \mathbf{u}_{\mathrm{g}}$ and $\mathbf{e}$, respectively. In the analyses of all traits, separate model terms in $\mathbf{u}_{\mathbf{0}}$ were assumed to be mutually independent, and thus $\mathbf{G}_{\mathbf{0}}$ was defined as $\oplus_{j=1}^{q} \mathbf{G}_{\mathbf{0} j}$, where $\mathbf{G}_{\mathbf{0} j}=\sigma_{j}^{2} \mathbf{I}_{n_{j}}$ is the variance matrix for the $j$ th random term $(j=1 \ldots q), \sigma_{j}^{2}$ is the variance parameter associated with the $j$ th term, $\mathbf{I}_{n_{j}}$ is an identity matrix of dimension $n_{j} \times n_{j}\left(n_{j}=\right.$ number of levels of the $j$ th term), and $\oplus$ is the direct sum operation. For $\mathrm{DBH}$, the variance matrix $\mathbf{G}_{\mathbf{g}}$ pertaining to family effects was defined as $\mathbf{G}_{\mathbf{g}}=\mathbf{C} \otimes \mathbf{I}_{n}$, where $\mathbf{C}$ is a $p \times p$ unstructured variance-covariance matrix with between-family variances within cross types on the diagonal and between-family covariances amongst cross types on the off-diagonal, $\mathbf{I}_{n}$ is an identity matrix of dimension $n \times n$, and $\otimes$ is the Kronecker product. For all traits, the residual terms from different cross types were assumed to be independent, leading to $\mathbf{R}=\oplus_{i=1}^{p} \mathbf{R}_{i}$ where, for the $i$ th cross type, $\mathbf{R}_{i}=\sigma_{e_{i}}^{2} \mathbf{I}_{N_{i}}$ is the variance matrix for the residual effects, $\sigma_{e_{i}}^{2}$ is the residual variance (for DBH, $\sigma_{e_{i}}^{2}$ corresponds to the within-family variance, and includes both genetic and microenvironmental effects), and $\mathbf{I}_{N_{i}}$ is an identity matrix of dimension $N_{i} \times N_{i}$. Thus, heterogeneity of variances amongst cross types for effects in $\mathbf{u}_{\mathbf{0}}$ (i.e. as mentioned above for the interaction between replicates and families for $\mathrm{DBH}), \mathbf{u}_{\mathrm{g}}$ and $\mathbf{e}$ was accounted for in the data analysis.

The (co)variance parameters were estimated by restricted maximum likelihood (REML, Patterson and Thompson, 1971). Leastsquares means (LSM) and standard errors of differences between LSM were estimated for each cross type and pairs of cross types, respectively. Pairwise differences of LSM were then tested using a $t$-test, and applying the Kenward and Roger (1997) approximation for computing the degrees of freedom associated with the test statistic. In particular, the comparisons SELF versus POL and OP versus POL provided an indication of the significance of population-level inbreeding depression (as defined below).

For DBH, the significance of the between-family variance was assessed for each cross type by using a one-tailed likelihood ratio (LR) test (Stram and Lee, 2004), and ignoring the family covariances amongst cross types. In addition, for a given pair of cross types, the homogeneity of between- or within-family variances was tested via two-tailed LR tests (e.g. as described in Costa e Silva et al., 2005). Initial analyses of SURV and BAH indicated that the variance estimate associated with the interaction between replicates and cross types was small and not statistically different from zero $(P>0.05)$ at all measurement ages, and thus this random term was not included in the final analyses of these traits. Normality of the residuals within each cross type was assessed with the Shapiro and Wilk (1965) test and the examination of quantile-quantile plots. In the analysis of SURV at age 4, the Shapiro and Wilk (1965) test rejected the null hypothesis of a normal distribution for the residuals in the POL cross type, but the deviation from normality was marginal. An arcsine transformation (i.e. $\sin ^{-1}(\sqrt{\mathrm{SURV}})$ ), with a correction for a proportion of survival equal to one, improved the residual normality, but led to similar conclusions in terms of significance tests for pairwise differences between cross-type LSM at age 4. Thus, only the analysis based on untransformed values is presented for SURV.

Population-level percentage inbreeding depression (ID) due to selfing was estimated for all traits and ages as (see Lande and Schemske, 1985):

$$
I D_{\text {self }}=\left(\operatorname{LSM}_{(\mathrm{pol})}-\operatorname{LSM}_{(\mathrm{self})} / \mathrm{LSM}_{(\mathrm{pol})}\right) \times 100
$$

where $\operatorname{LSM}_{(\mathrm{pol})}$ and $\operatorname{LSM}_{\text {(self) }}$ are the overall least-squares means for POL and SELF, respectively. This provides an estimate of the relative decrease in a trait overall mean caused by reduced heterozygosity with inbreeding. Similarly, $I D$ due to open pollination $\left(I D_{\mathrm{op}}\right)$ was calculated by replacing $\operatorname{LSM}_{(\text {self) }}$ with $\operatorname{LSM}_{(\mathrm{op})}$ in (3). $I D_{\text {op }}$ will be a function of both $I D_{\text {self }}$ and outcrossing rate (Charlesworth, 2006). Population-level outcrossing rate $(t)$ was estimated for each trait and 

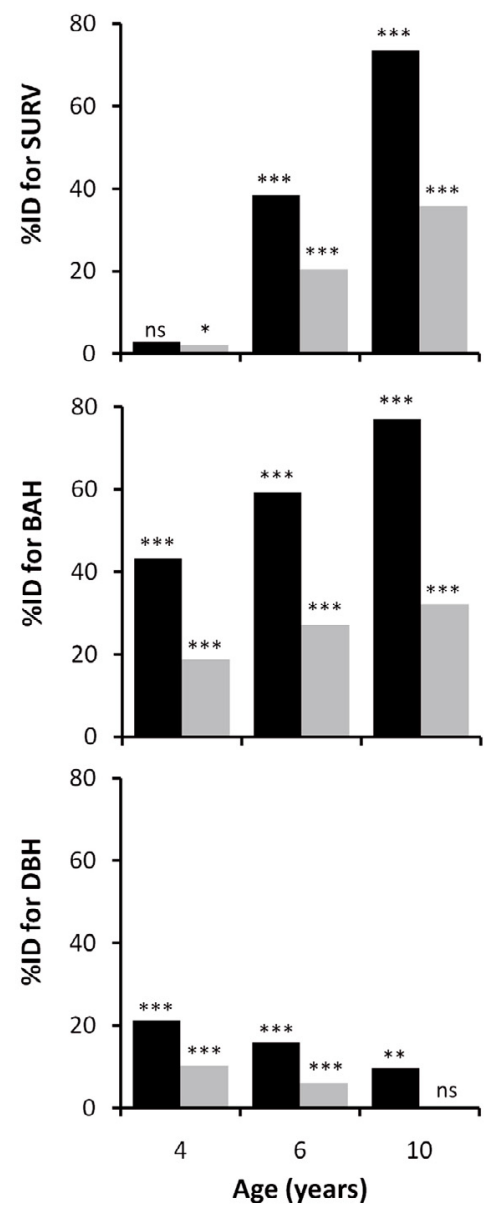

Figure 1. Inbreeding depression (\% ID) due to selfing (black) and open pollination (grey) for survival (SURV), basal area per hectare (BAH) and stem diameter of surviving trees (DBH) at different ages from planting. The statistical significance of pairwise differences between the estimated least-squares means of the polymix crossing and the self or open-pollinated populations is indicated for each trait and age (see also Appendix ${ }^{1} 1$ ): ***, $P \leq 0.001$; **, $P \leq 0.01$; $*, P \leq 0.05 ; \mathrm{ns}, P>0.05$.

age as (see Charlesworth and Charlesworth, 1987):

$$
t=\left(\mathrm{LSM}_{(\mathrm{op})}-\mathrm{LSM}_{(\mathrm{self})} / \mathrm{LSM}_{(\mathrm{pol})}-\mathrm{LSM}_{(\mathrm{self})}\right) .
$$

ASReml (Gilmour et al., 2006) and SAS (SAS Institute Inc., 2004) were the statistical software packages used in the data analysis.

\section{RESULTS}

\subsection{Population-level inbreeding depression and outcrossing rate}

Estimates of LSM for each cross type, ID (due to both selfing and open pollination) and $t$ are provided in Appendix ${ }^{1} 1$ for SURV, BAH and DBH measured at ages 4, 6 and 10 years

\footnotetext{
${ }^{1}$ Appendices are available online only at www.afs-journal.org.
}

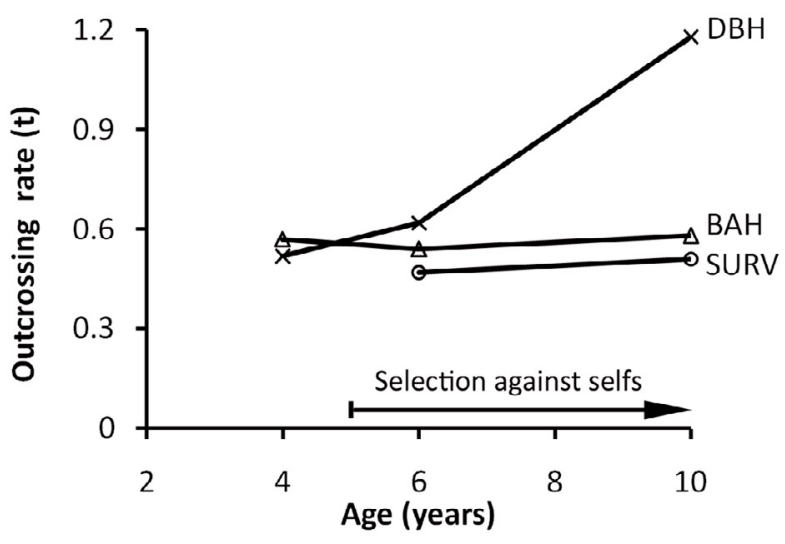

Figure 2. Changes in estimated outcrossing rate $(t)$ in the openpollinated population with age for survival (SURV), basal area per hectare $(\mathrm{BAH})$ and stem diameter of surviving trees $(\mathrm{DBH})$. An estimate of $t$ is not presented for SURV at age 4 years, as the pairwise difference between the least-squares means of the self population and either open-pollinated or polymix progenies was not statistically significant (Appendix 1). An arrow is depicted to indicate that accumulated mortality of selfs is taking place following age 4 years.

from planting, and key results for $I D$ and $t$ are summarised in Figures 1 and 2, respectively.

At age 4, the overall mean SURV was high (ranging from 91.4 to $94 \%$ ) for all cross types (Appendix ${ }^{1} 1$ ). $I D_{\text {self }}$ for SURV was not significant $(P>0.05)$ at this age but was rapidly manifested thereafter (Fig. 1). At ages 6 and 10, SELF had significantly $(P \leq 0.001)$ lower mean SURV (55.2 and $21.9 \%$ ) than that of POL (89.8 and $82.9 \%$ ), resulting in $I D_{\text {self }}$ of 38.5 and $73.6 \%$, respectively (Appendix ${ }^{1} 1$ and Fig. 1). $I D_{\text {self }}$ for the DBH of surviving trees was evident at all ages. However, in contrast to the trend in SURV, $I D_{\text {self }}$ for DBH actually decreased with age from $21.3 \%$ at 4 years to $9.7 \%$ at 10 years (Fig. 1). Integrating SURV and DBH at the main plot level showed that, even in the absence of direct competition, BAH was significantly $(P \leq 0.001)$ reduced in the SELF compared with the POL population at all ages. As with SURV, $I D_{\text {self }}$ in BAH increased with age from $43.2 \%$ at 4 years to $77 \%$ at 10 years, and in all cases was higher than that observed for SURV and DBH alone (Fig. 1). Assuming that the relationship between the mean phenotype and inbreeding coefficient is linear, our levels of $I D_{\text {self }}$ indicate that for every 0.1 increase in the inbreeding coefficient there will be a reduction in the trait mean value of about 8 to $15 \%$ for SURV, 9 to $15 \%$ for BAH, and 2 to $4 \%$ for the DBH of survivors, at the examined ages.

The OP performance was mostly intermediate between SELF and POL, consistent with the presence of both selfs (and possibly other forms of inbreeding) and outcross progeny. Except for 4-year SURV and 10-year DBH, the performance of OP was highly significantly $(P \leq 0.001)$ better than that of the SELF and poorer than that of the POL (Appendix ${ }^{1} 1$ ). The age trends in $I D_{\text {op }}$ were similar to $I D_{\text {self }}$ (Fig. 1). The $I D_{\text {op }}$ for SURV and BAH increased between ages 4 and 10, from 2.1 to $35.8 \%$ for SURV and from 18.7 to $32.2 \%$ for BAH. Conversely, $I D_{\mathrm{op}}$ for the DBH of surviving trees decreased from 
Table I. Estimated family and within-family variances, and respective coefficients of variation, for DBH based on progeny data from three crossing designs - selfing (SELF), open pollination (OP) and outcrossing with Polymix (POL) - at different ages from planting. The significance probabilities refer to one-tailed likelihood ratio tests, used to test the departure of the family variance estimates from zero.

\begin{tabular}{cccccccc}
\hline Age (years) & \multicolumn{3}{c}{ Family variance } & & \multicolumn{3}{c}{ Within-family variance } \\
\cline { 2 - 3 } & SELF & OP & POL & & SELF & OP & POL \\
\hline 4 & 1.21 & 1.49 & 0.24 & & 5.64 & 6.75 & 4.03 \\
& $(12.9)$ & $(12.6)$ & $(4.5)$ & & $(27.9)$ & $(26.8)$ & $(18.6)$ \\
& $P \leq 0.001$ & $P \leq 0.001$ & $P \leq 0.001$ & & & & \\
6 & 2.62 & 1.29 & 0.50 & & 6.14 & 9.09 & 5.22 \\
& $(14.6)$ & $(9.2)$ & $(5.4)$ & & $(22.3)$ & $(24.3)$ & $(17.3)$ \\
& $P \leq 0.001$ & $P \leq 0.001$ & $P \leq 0.001$ & & & & \\
10 & 7.40 & 1.61 & 1.92 & & 22.71 & 21.11 & 13.80 \\
& $(17.1)$ & $(7.1)$ & $(7.9)$ & & $(30.0)$ & $(25.7)$ & $(21.1)$ \\
& $P \leq 0.001$ & $P \leq 0.001$ & $P \leq 0.001$ & & & \\
\hline
\end{tabular}

The coefficients of variation are given in percentage within parenthesis, and were calculated using estimated least-squares means for the corresponding cross types.

a significant $10.2 \%$ and $6.1 \%$ at ages 4 and 6 , respectively, to virtually zero at age 10 . However, as with the SELF plots, even with the better relative performance of surviving trees, after 10 years the productivity of the OP plots was still significantly less (i.e. $32 \% I D_{\text {op }}$ for BAH) than the POL plots on a per hectare basis.

With the exception of DBH at age 10 and SURV at age 4 , estimates of outcrossing rate $(t)$ in the OP progenies were relatively stable, ranging from 0.47 to 0.51 (average $=0.49$, $n=2$ ), 0.54 to 0.58 (average $=0.56, n=3$ ) and 0.52 to 0.62 (average $=0.57, n=2$ ) for SURV, BAH and DBH, respectively (Appendix ${ }^{1} 1$ ). Despite the stability in $t$ estimates from $\mathrm{BAH}$ and later age SURV, when DBH is used there is an increase in $t$ with age in the surviving cohort, from 0.52 at age 4 to over 1 at age 10 (Fig. 2). The later age estimate of $t$ for DBH is likely to be biased upwards, as the comparison of the mean performances for DBH may be affected by different competition intensities within the cross-type plots through differential mortality. Nevertheless, this result, coupled with the evidence of high $I D_{\text {self }}$ for SURV, argues that by age 10 the surviving cohort in the OP mainly comprises outcrosses.

\subsection{Observational variances}

Inbreeding not only impacts on the population mean performance of E. globulus, but also on the size and distribution of both between- $\left(\hat{\sigma}_{\mathrm{f}}^{2}\right)$ and within-family $\left(\hat{\sigma}_{\mathrm{wf}}^{2}\right)$ DBH variance estimates, as shown in Table I. Table II presents the results from LR tests used to test the homogeneity of $\hat{\sigma}_{f}^{2}$ or $\hat{\sigma}_{w f}^{2}$ between a pair of cross types for $\mathrm{DBH}$ at a given age. The estimated variances due to the interaction between replicates and families are not presented, but they were generally small and not significantly $(P>0.05)$ different from zero except for POL at age 4 , in which case the estimate was marginally significant only (i.e. $P=0.02)$. The $\hat{\sigma}_{\mathrm{f}}^{2}$ values were significantly $(P \leq 0.001)$ different from zero for all cross types and ages.

The $\hat{\sigma}_{\mathrm{f}}^{2}$ values increased with age for the SELF $\left(\hat{\sigma}_{\mathrm{f}(\mathrm{self})}^{2}\right)$ and POL $\left(\hat{\sigma}_{\mathrm{f}(\mathrm{pol})}^{2}\right)$ cross types as did the coefficient of betweenfamily variation $\left(C V_{\mathrm{f}}\right)$ (Tab. I). At every age, there was more
Table II. Significance probabilities from two-tailed likelihood ratio tests used to test the homogeneity of family or within-family variances between a given pair of crossing designs, and estimated at different ages from planting.

\begin{tabular}{lllccc}
\hline Age (years) & \multicolumn{3}{c}{ Family variance } & \multicolumn{2}{c}{ Within-family variance } \\
\hline \multirow{4}{*}{4} & & SELF & OP & SELF & OP \\
& & & & \\
& OP & $>0.05$ & & 0.029 & \\
6 & POL & $\leq 0.001$ & $\leq 0.001$ & $\leq 0.001$ & $\leq 0.001$ \\
& & & & & \\
& OP & $>0.05$ & & $\leq 0.001$ & \\
10 & POL & 0.002 & 0.012 & $>0.05$ & $\leq 0.001$ \\
& OP & 0.022 & & & \\
& POL & 0.033 & $>0.05$ & $\leq 0.001$ & $\leq 0.001$ \\
\hline
\end{tabular}

The crossing designs are selfing (SELF), open pollination (OP) and outcrossing with Polymix (POL).

variation between SELF families than POL families, as evident by both the variances and coefficients of variation. The difference between $\hat{\sigma}_{\mathrm{f}(\mathrm{self})}^{2}$ and $\hat{\sigma}_{\mathrm{f}(\mathrm{pol})}^{2}$ was significant $(P \leq 0.05)$ at all ages (Tab. II). The $\hat{\sigma}_{\mathrm{wf}}^{2}$ values increased from age 4 to 10 for both SELF and POL progenies, although the coefficient of within-family variation $\left(C V_{\text {wf }}\right)$ decreased from age 4 to 6 , and then increased at age 10 (Tab. I). Nevertheless, the $\hat{\sigma}_{\mathrm{wf}}^{2}$ and $C V_{\mathrm{wf}}$ values were always greater for SELF compared with POL families. Highly significant $(P \leq 0.001) \hat{\sigma}_{\mathrm{wf}}^{2}$ heterogeneity was apparent between SELF and POL at ages 4 and 10 (Tab. II), indicating that inbreeding increased the withinfamily variances.

The variance between OP families $\left(\hat{\sigma}_{\mathrm{f}(\mathrm{op})}^{2}\right)$ was initially significantly greater than $\hat{\sigma}_{\mathrm{f}(\mathrm{pol})}^{2}$ and not significantly different from $\hat{\sigma}_{\mathrm{f}(\mathrm{self})}^{2}$, but the reverse was the case by age 10 years (Tab. I and II). This trend for OP to become more similar to POL with age was also evident in $C V_{\mathrm{f}(\mathrm{op})}$ which, in contrast to that in the SELF and POL populations, decreased gradually with age. As indicated by both $\hat{\sigma}_{\text {wf }}^{2}$ and $C V_{\text {wf }}$, the OP families were significantly $(P \leq 0.001)$ more variable than POL families at all ages 
(Tabs. I and II). They also exhibited greater $\hat{\sigma}_{\mathrm{wf}}^{2}$ than SELF at ages 4 and 6 , although at age 4 the variance heterogeneity was significant at the 5\% level only and the increase in variability was only evident for $C V_{\mathrm{wf}}$ at age 6 (Tabs. I and II). At age 10, the $\hat{\sigma}_{\mathrm{wf}}^{2}$ values for SELF and OP were similar (Tab. I) and not significantly different $\left(P>0.05\right.$, Tab. II), but the $C V_{\text {wf }}$ was intermediate between that of the SELF and POL progenies.

\section{DISCUSSION}

\subsection{Population-level inbreeding depression and outcrossing rate}

The $I D_{\text {self }}$ detected in the present study for SURV (74\%) and BAH $(77 \%)$ after 10 years from planting is well above the $28 \%$ average for growth and reproductive phase of outcrossing angiosperms reported by Husband and Schemske (1996), and is the highest yet reported for Eucalyptus. For SURV, Hardner and Potts (1997) obtained $I D_{\text {self }}$ values of 50 and $67 \%$ in 10- and 15-year-old E. regnans, respectively, and insignificant $I D_{\text {self }}$ was found by Hardner and Tibbits (1998) in 9-yearold $E$. nitens. There are no comparable eucalypt studies with which to compare our levels of $I D_{\text {self }}$ for $\mathrm{BAH}$, as other studies have not integrated SURV and growth (i.e. DBH or basal area) of survivors into an estimate of overall productivity per hectare. However, individual tree estimates of $I D_{\text {self }}$ for basal area (e.g. $47 \%$ for E. regnans, Hardner and Potts, 1997; 35\% for E. nitens, Hardner and Tibbits, 1998) or conic volume (e.g. $47 \%$ and $48 \%$ for E. globulus, Hardner and Potts, 1995, and Hardner et al., 1998, respectively) at about 4 years from planting are similar to our estimate for BAH (43\%), and comparable given that $I D_{\text {self }}$ for SURV was not significant at age 4 (Fig. 1; Hardner and Potts, 1995). Our $21 \% I D_{\text {self }}$ for DBH at 4 years is also similar to that reported at a comparable age for several eucalypt species (e.g. $18 \%$ for E. regnans at 45 months, Griffin and Cotterill, 1988; 22\% for E. nitens at 4 years, Hardner and Tibbits, 1998), including E. globulus (e.g. 24\% at 43 months, Hardner and Potts, 1995). The similarity of these studies at age 4 years argues that our atypically high inbreeding depression for SURV and BAH is a later age phenomenon arising through an accentuation of self mortality following age 4 . This was evident despite our trial design minimising competition amongst cross types, and most likely reflects the high genetic load in the E. globulus population studied. It is unlikely to be due to random sampling effects of the parental population, as our study was based on more than twice the number of base parents as previous studies on inbreeding in Eucalyptus spp. (e.g. 11 parents, Hardner and Potts, 1995; 13 parents, Hardner and Potts, 1997; 12 parents, Hardner and Tibbits, 1998; 7 parents, Hardner et al., 1998)

Our declining $I D_{\text {self }}$ for DBH with age (Fig. 1) contrasts with the stable trend found for individual tree basal area in E. regnans (Hardner and Potts, 1997). This stability in E. regnans was due to a balance between the mortality of smaller individuals and competition increasing $I D_{\text {self }}$ in the surviving cohort with age. The difference between studies may be a reflection of the different trial designs, as selfs were growing in direct competition with outcrosses in the E. regnans trial but not in our E. globulus trial. When selfs and outcrosses are directly competing, as they would in open-pollinated families derived from mixed mating, competition with faster growing outcrossed progenies would be expected to accentuate the levels of $I D_{\text {self }}$ (Hardner and Potts, 1997). However, with our field design, the significantly higher mortality in SELF and OP compared with POL at ages 6 and 10, would mean that the $\mathrm{DBH}$ of the surviving trees within the SELF and OP main plots would have been enhanced compared with the POL progeny. This would result in an overestimation of the performance of SELF and OP survivors relative to those from the POL for DBH at later ages, and suggests that the $I D_{\text {self }}$ observed for DBH at ages 6 and 10 is underestimated. Indeed, a higher level of $I D_{\text {self }}$ would be expected under direct competition with the non-inbred half-sibs, as would occur in open-pollinated families and in the wild.

In agreement with previous studies in Eucalyptus ssp. (Griffin and Cotterill, 1988; Hardner and Potts, 1995; 1997; Hardner and Tibbits, 1998), the performance of the native stand OP was mostly intermediate between SELF and POL (Appendix ${ }^{1} 1$ ), indicating the presence of both selfs (and possibly other forms of inbreeding, Hardner et al., 1998) and outcross progeny within a given OP family. With our field design, once cross-type differences in SURV occur, BAH provides the best estimate of the overall $I D_{\text {self }}$ at the population level. The average of the outcrossing rates derived from comparing the relative performance of cross types for BAH $(0.56, n=3)$ was identical to an estimate of $t$ obtained by Hardner and Potts (1995) from E. globulus conic volume data at 43 months, but slightly lower than estimates reported by Griffin and Cotterill (1988) for E. regnans at 45 months (i.e. 0.67 and 0.69 for DBH and conic volume, respectively). Such indirect estimates of outcrossing rates will be influenced by numerous factors, including the presence of bi-parental inbreeding (Hardner et al., 1998), as well as whether the outcrossing that occurs under natural open pollination is genetically equivalent to the experimental controlled outcrosses (such as POL). In our case, we would argue that the later is not an issue as the pollen parents were derived from unrelated samples from the same population as the females. Our estimate of $t$ is markedly less than estimates (which exceed 0.86) obtained from upper canopies in continuous native forests of E. globulus, using microsatellite markers (Jones, 2005; Mimura et al., 2009). However, given that the lower canopy position from which our OP seed was collected and the fragmented nature of the native E. globulus forest in which the parents were growing are expected to reduce outcrossing (Mimura et al., 2009; Patterson et al., 2001; 2004), our indirect estimates of $t$ were only slightly lower than previous estimates from mating system studies. For example, outcrossing rates estimated using allozymes (Patterson et al., 2004) or a rare chlorophyll mutation (McGowen et al., 2004b; Patterson et al., 2001) at a similar canopy position from several of the native seed parents used in this study ranged from 0.27 to 0.99 , and the average across 8 trees in the population tested was 0.65 . Allozymes may underestimate outcrossing rates by up to $10 \%$ compared with estimates derived from the more variable microsatellites (Byrne, 2008). However, a recent microsatellite study of 20 trees in a similar fragmented 
landscape from the same geographic area yielded an average multi-locus outcrossing rate of 0.66 for upper canopy samples (Mimura et al., 2009). Our lower estimate of $t$ compared to these direct estimates could be due to biparental inbreeding (Hardner et al., 1998; Jones, 2005), and differences with Mimura et al. (2009) could also reflect our lower canopy sampling.

Our $I D_{\text {op }}$ estimate for the DBH of survivors at age 4 years $(10 \%)$ is slightly lower than similarly age reports for $\mathrm{DBH}$ in other eucalypt species (e.g. 13\% for E. nitens, Hardner and Tibbits, 1998), including E. globulus (e.g. 13\%, Hardner and Potts, $1995 ; 16 \%$, Volker, 2002). The $I D_{\text {op }}$ for DBH was subsequently reduced with age (Fig. 1), and the estimate of the OP outcrossing rate based on $\mathrm{DBH}$ increased to over unity by age 10 (Fig. 2). This increase in the proportion of outcrosses in the OP population with age is expected from the differentially high mortality of selfs following age 4 , and argues that by age 10 the surviving OP cohort mainly comprises outcrosses. While the $t$ estimate at age 10 is no doubt inflated by the low mortality and high inter-tree competition in the POL main plots used as controls, this result is consistent with an experiment with E. regnans (Hardner and Potts, 1997). It is also consistent with the commonly reported decrease in inbreeding coefficients between the OP seed and adult cohorts observed in allozyme studies of native populations of eucalypts (Potts and Wiltshire, 1997) and a microsatellite study of an E. globulus population (Jones, 2005).

\subsection{Observational variances}

The components of between- and within-family variation estimated for DBH increased in the SELF compared with the POL progeny (Tab. I), in agreement with results that have been reported in experiments with E. globulus (Hardner and Potts, 1995), other Eucalyptus spp. (Griffin and Cotterill, 1988; Hardner and Potts, 1995, 1997) and other tree genera (Wu et al., 1998) after one or two generations of selfing. The magnitude of $\hat{\sigma}_{\mathrm{f}(\mathrm{self})}^{2}$ relative to $\hat{\sigma}_{\mathrm{f}(\mathrm{pol})}^{2}$ may depend on the genetic mechanisms underlying inbreeding depression. Results from several studies have indicated that the betweenfamily variance in selfed progeny is expected to be substantially greater than that in outcross progeny when inbreeding depression is caused by the expression of rare deleterious alleles in homozygous individuals (Kelly, 1999; 2005; Moorad and Wade, 2005). In particular, Kelly (2005) studied the development of the selfed to outcross between-family variances as a function of the average dominance degree of rare deleterious alleles $(h)$ and, for partially recessive alleles with $h=0.2$, the expected ratio was about 5 when the base parents were not inbred (increasing to 10 for fully inbred parents). Alternatively, using a model in which the hypothetical cause of inbreeding depression was the reduction in the frequency of heterozygotes at overdominant loci, Kelly (2005) found that the discrepancy between the variances of the selfed and outcross families was not large. The $\hat{\sigma}_{\mathrm{f}(\mathrm{self})}^{2} / \hat{\sigma}_{\mathrm{f}(\mathrm{pol})}^{2}$ ratio varied from 4 (age 10 ) to 5 (ages 4 and 6) in the present study which, according to Kelly's (2005) theoretical expectations, suggests that rare and partially recessive deleterious alleles are important in inducing inbreeding depression for DBH. The expression of rare recessive deleterious alleles under inbreeding may also contribute to enhance the within-family variance in selfed progeny (Robertson, 1952). Yet, the raise in within-family variance with inbreeding is also likely to reflect an increase in environmental variance, as inbred progeny may become more susceptible to changes in the environment than outcross progeny (Lerner, 1954). However, the difference between SELF and POL in levels of environmental sensitivity is expected to be small at age 4 because most selection against inbred trees occurred after this age (Fig. 1), including a greater heterogeneity in inter-tree competition.

The similar between-family variation for SELF and OP at age 4 (Tabs. I and II) is consistent with the OP families containing a large proportion of inbred individuals. However, over time, between-family variation in the OP progeny became reduced in relation to SELF and approached that among the POL families (Tab. I), indicating that the inflation of the OP family variance due to inbreeding decreased with age. This most likely reflects the increased mortality of inbred individuals within OP families, hence purging deleterious alleles that would have affected between-family variation for DBH. Thus, before age 10, estimates of additive genetic variances derived from OP progenies could be inflated due to the contribution of the covariance between inbred relatives to the OP betweenfamily variances. In addition, variable inbreeding among the $\mathrm{OP}$ individuals (e.g. due to variation in selfing rates) is expected to promote differential inbreeding depression among the OP families, and thus further the overestimation bias in $\hat{\sigma}_{\mathrm{f}(\mathrm{op})}^{2}$ (Cockerham and Weir, 1984). However, at age 4, the $\hat{\sigma}_{\mathrm{f}}^{2}$ for OP was not significantly different $(P>0.05$, Tab. II) from that in the SELF population, where a constant inbreeding level of 0.5 is present, suggesting that variable inbreeding among the OP individuals may not have been the main cause of differential inbreeding depression among the OP families for $\mathrm{DBH}$ (see also Costa e Silva et al., 2010, where comparable estimates of variances in family-level inbreeding depression were obtained for SELF and OP progenies at age 4).

The within-family variation was always greater for OP compared with POL families. The high $\hat{\sigma}_{\mathrm{wf}}^{2}$ values we observed in native OP families compared with outcross progeny have been previously reported for E. globulus (Hardner and Potts, 1995; Hodge et al., 1996). This would be expected, firstly, as this term could contain an effect of $I D_{\text {self }}$ within OP families as they comprise both selfed and non-inbred offspring and, secondly, the greater variance expected among these selfed individuals as discussed previously. The age dynamics in $\hat{\sigma}_{\mathrm{wf}}^{2}$ of the OP families reflects the balancing trends associated with: (i) the selective mortality of selfs within these families (Fig. 1); (ii) the trend for competition to accentuate the expression of the deleterious effects of inbreeding with age (e.g. Hardner and Potts, 1997); and (iii) the increasingly heterogeneous competitive environment in our OP main plots compared with the POL plots through the increasing mortality of selfs with age. In all cases, $\hat{\sigma}_{w f}^{2}$ was greater than $\hat{\sigma}_{f}^{2}$ within a given cross type. However, the difference in $\hat{\sigma}_{w f}^{2}$ relative to 
$\hat{\sigma}_{\mathrm{f}}^{2}$ was more accentuated with age for OP progeny, whereas the reverse trend was observed for the other cross types. This was the result of the OP population resembling the SELF population in its variance structure at age 4 , but becoming more similar to the POL population by age 10 (Tab. I). This convergence occurred over the period when differential mortality of the selfs was greatest (i.e. $I D_{\text {self }}$ for SURV; Fig. 1), and is no doubt partly due to the elimination of selfs from the OP population.

\subsection{Implications}

While most eucalypts exhibit a mixed mating system (with outcrossing rates in the wild averaging $74 \%$ across 23 species, Byrne, 2008), there is increasing evidence for strong postdispersal selection against the products of self fertilisation (Griffin and Cotterill, 1988; Hardner and Potts, 1995, 1997; Hardner et al., 1998; Appendix ${ }^{1} 1$ and Fig. 1, present study). Few selfs are likely to survive to reproductive maturity in native populations, thus preventing a build up of inbreeding over generations. With a genetic basis for variation in inbreeding depression in seed set, as appears to be the case in E. globulus (McGowen et al., 2004a), such strong selection against selfs would alone be expected to result in the evolution of complete outcrossing (Goodwillie et al., 2005; Hardner and Potts, 1997). Why eucalypts (Byrne, 2008) or other plant species (Vogler and Kalisz, 2001) consistently exhibit a mixed mating system in the face of such selection is unclear (Charlesworth, 2006; Goodwillie et al., 2005), although with a high seed output per tree the reproductive cost of selfing is probably low and inbreeding depression may well be countered by factors such as reproductive assurance at low pollinator or flowering plant densities (Charlesworth, 2006; Hardner and Potts, 1997).

With time, the between-family variance (and thus the additive genetic variation) comprised an increasingly component of the phenotypic variation in growth in our noninbred population. However, in open-pollinated populations, age trends are confounded with significant size-dependent mortality (Chambers et al., 1996; Hardner and Potts, 1997) and a change in the genetic composition of the population due to the loss of inbreds and purging of deleterious genetic effects. The duration and extent to which inbreeding effects dominate the genetic variation in growth during stand development will depend upon numerous factors, including the original outcrossing rate. The importance of these inbreeding effects have no doubt been accentuated in the open-pollinated population studied here due to the relatively low outcrossing rate of the founder parents in the remnant population sampled. However, these effects are unlikely to be as important in offspring populations from dense native forest of $E$. globulus (Mimura et al., 2009), but will be expected to be of comparable levels in natural populations where tree density is naturally low (e.g. native woodlands) or when population numbers of reproductive trees are reduced following catastrophic events such as wildfire or during founder events (Petit et al., 2004).

The base population trees studied were remnants of native forest which was fragmented through clearing for agriculture.
Environmental tree plantings in such landscapes are increasing, often for multiple objectives including carbon sequestration, water quality and biodiversity restoration. The use of local seed sources for such forest restoration is often seen as a "safe" option, which optimises adaptation to the local environment, and minimises genetic contamination of the local native gene pools (Broadhurst et al., 2008). However, this approach is increasingly being challenged as there is uncertainty as to the future adaptive advantage of local germplasm in the face of climate and other environmental (e.g. salinity) change, as well as the fact that local seed may be scarce and of poor genetic quality (Broadhurst et al., 2008). Higher inbreeding levels have clearly been demonstrated in seed collected from such remnant forests (Mimura et al., 2009), and the large main plot plantings used in the present study approximate the relative productivity expected for these cross types in larger-scale forest plantings. While the possibility of full site occupancy later in the life cycle cannot be dismissed, it is clear that even with the relative performance of surviving trees increasing with age, after 10 years the productivity of the main plots derived from the open-pollinated seed collected from the remnant trees was still significantly less than the non-inbred progeny on a per hectare basis (i.e. $32 \% I D_{\text {op }}$ for $\mathrm{BAH}$ ). While such losses through inbreeding would not be fully realized when compared to the alternative of wild seed from large, continuous stands (Mimura et al., 2009), the present study argues that inbreeding depression in open-pollinated seed collected from remnant forest will be a significant force countering fitness benefits from local adaptation.

Acknowledgements: We thank Gunns Ltd for provision of the trial site. Funding for crossing, trial establishment and a $\mathrm{PhD}$ scholarship $(\mathrm{CH})$ was provided by the CRC for Temperate Hardwood Forestry. Trial measurements were supported by the CRC for Sustainable Production Forestry and an Australian Research Council Linkage Grant (LP0884001). The financial support given by Fundação para a Ciência e Tecnologia (Lisboa, Portugal) through the Ciência 2007 initiative to the senior author and by the Australian Research Council (BMP) is gratefully acknowledged.

\section{REFERENCES}

Broadhurst L.M., Lowe A.J., Coates D.J., Cunningham S.A., McDonald M.W., Vesk P.A., and Yates C.J., 2008. Seed supply for broadscale restoration: maximizing evolutionary potential. Evol. Appl. 1: 587597.

Byrne M., 2008. Phylogeny, diversity and evolution of eucalypts. In: Sharma A.K. and Sharma A. (Eds.), Plant Genome: Biodiversity and Evolution, Part E: Phanerogams-Angiosperm, Science Publishers Enfield, Volume 1, pp. 303-346.

Chambers P.G.S., Borralho N.M.G., and Potts B.M., 1996. Genetic analysis of survival in Eucalyptus globulus ssp. globulus. Silvae Genet. 45: 107-112.

Charlesworth D., 2006. Evolution of plant breeding systems. Curr. Biol. 16: 726-735.

Charlesworth D. and Charlesworth B., 1987. Inbreeding depression and its evolutionary consequences. Annu. Rev. Ecol. Syst. 18: 237-268.

Cockerham C.C. and Weir B.S., 1984. Covariances of relatives stemming from a population undergoing mixed self and random mating. Biometrics 40: 157-164. 
Costa e Silva J., Dutkowski G.W., and Borralho N.M.G., 2005. Acrosssite heterogeneity of genetic and environmental variances in the genetic evaluation of Eucalyptus globulus trials for height growth. Ann. For. Sci. 62: 183-191.

Costa e Silva J., Hardner C.M., and Potts B.M., 2010. Genetic variation and parental performance under inbreeding for growth in Eucalyptus globulus. Ann. For. Sci. 67: 606.

Ellstrand N.C. and Elam D.R., 1993. Population genetic consequences of small population size: implications for plant conservation. Annual Review of Ecology and Systematics 24: 217-42.

Gilmour A.R., Gogel B.J., Cullis B.R., and Thompson R., 2006. ASReml User Guide Release 2.0. VSN International Ltd, Hemel Hempstead, UK.

Goodwillie C., Kalisz S., and Eckert C.G., 2005. The evolutionary enigma of mixed mating systems in plants: Occurrence, theoretical explanations, and empirical evidence. Annu. Rev. Ecol. Evol. Syst. 36: $47-79$.

Griffin A.R. and Cotterill P.P., 1988. Genetic variation in growth of outcrossed, selfed and open-pollinated progenies of Eucalyptus regnans and some implications for breeding strategy. Silvae Genet. 37: 124-131.

Hardner C.M. and Potts B.M., 1995. Inbreeding depression and changes in variation after selfing Eucalyptus globulus subsp. globulus. Silvae Genet. 44: 46-54.

Hardner C.M. and Potts B.M., 1997. Postdispersal selection following mixed mating in Eucalyptus regnans. Evolution 51: 103-111.

Hardner C.M. and Tibbits W.N., 1998. Inbreeding depression for growth, wood and fecundity traits in Eucalyptus nitens. For. Genet. 5: 11-20.

Hardner C.M., Potts B.M., and Gore P.L., 1998. The relationship between cross success and spatial proximity of Eucalyptus globulus ssp. globulus parents. Evolution 52: 614-618.

Hodge G.R., Volker P.W., Potts B.M., and Owen J.V., 1996. A comparison of genetic information from open-pollinated and control-pollinated progeny tests in two eucalypt species. Theor. Appl. Genet. 92: 5363.

Husband B.C. and Schemske D.W., 1996. Evolution of the magnitude and timing of inbreeding depression in plants. Evolution 50: 54-70.

Jones T.H., 2005. Population Genetics of Native and Domesticated Eucalyptus globulus. Unpublished Ph.D. thesis, School of Plant Science, University of Tasmania, Hobart.

Kelly J.K., 1999. An experimental method for evaluating the contribution of deleterious mutations to quantitative trait variation. Genet. Res. 73: 263-273

Kelly J.K., 2005. Family level inbreeding depression and the evolution of plant systems. New Phytol. 165: 55-62.

Kenward M.G. and Roger J.H., 1997. The precision of fixed effects estimates from restricted maximum likelihood. Biometrics 53: 983-997.

Klekowski E.J., 1988. Genetic load and its causes in long-lived plants. Trees 2: 195-203.

Lande R. and Schemske D.W., 1985. The evolution of self-fertilisation and inbreeding depression in plants. I. Genetic models. Evolution 39: 24-40.

Lerner I.M., 1954. Genetic Homeostasis. Oliver and Boyd, Edinburgh, Scotland

Lopez G.A., Potts B.M., and Tilyard P.A., 2000. F1 hybrid inviability in Eucalyptus: the case of E. ovata $\times$ E. globulus. Heredity 85: 242-250.

Lynch M. and Walsh B., 1998. Genetics and Analysis of Quantitative Traits. Sinauer Associates, Sunderland, MA, USA.

McGowen M., Potts B.M., Vaillancourt R., Gore P., Williams D., and Pilbeam D., 2004a. The genetic control of sexual reproduction in Eucalyptus globulus. In: Borralho N.M.G., Pereira J.S., Marques C., Coutinho J., Madeira M., and Tomé M. (Eds), Eucalyptus in a Changing World, Proceedings IUFRO Conference, Aveiro, Portugal.
RAIZ, Instituto Investigação de Floresta e Papel, Portugal, pp. 104-108.

McGowen M.H., Williams D.R., Potts B.M., and Vaillancourt R.E., 2004b. Stability of outcrossing rates in Eucalyptus globulus seedlots. Silvae Genet. 53: 42-44.

Mimura M., Barbour R.C., Potts B.M., Vaillancourt R.E., and Watanabe K.N., 2009. Comparison of contemporary mating patterns in continuous and fragmented Eucalyptus globulus native forests. Mol. Ecol. 18: 4180-4192.

Moorad J.A. and Wade M.J., 2005. A genetic interpretation of the variation in inbreeding depression. Genetics 170: 1373-1384.

Patterson B., Vaillancourt R.E., and Potts B.M., 2001. Eucalypt seed collectors: beware of sampling seed lots from low in the canopy! Aust. For. 64: 139-142.

Patterson B., Vaillancourt R.E., Pilbeam D.J., and Potts B.M., 2004. Factors affecting outcrossing rates in Eucalyptus globulus. Aust. J. Bot. 52: 773-780.

Patterson H.D. and Thompson R., 1971. Recovery of inter-block information when block sizes are unequal. Biometrika 58: 545-554.

Petit R.J., Bialozyt R., Garnier-Gere P., and Hampe A., 2004. Ecology and genetics of tree invasions: from recent introductions to Quaternary migrations. For. Ecol. Manage. 197: 117-137.

Potts B.M. and Wiltshire R.J.E., 1997. Eucalypt genetics and genecology. In: Williams J.E. and Woinarski J.C.Z. (Eds), Eucalypt Ecology: Individuals to Ecosystems, Cambridge University Press, Cambridge, pp. 56-91.

Potts B.M., Vaillancourt R.E., Jordan G., Dutkowski G.W., Costa e Silva J., McKinnon G., Steane D., Volker P., Lopez G., Apiolaza L., Li Y., Marques C., and Borralho N.M.G., 2004. Exploration of the Eucalyptus globulus gene pool. In: Borralho N.M.G., Pereira J.S., Marques C., Coutinho J., Madeira M., and Tomé M. (Eds), Eucalyptus in a Changing World, Proceedings IUFRO Conference, Aveiro, Portugal. RAIZ, Instituto Investigação de Floresta e Papel, Portugal, pp. 46-61.

Potts B.M., McGowen M.H., Williams D.R., Suitor S., Jones T.H., Gore P.L., and Vaillancourt R.E., 2008. Advances in reproductive biology and seed production systems of Eucalyptus: The case of Eucalyptus globulus. Southern Forests 70: 145-154.

Robertson A., 1952. The effect of inbreeding on the variation due to recessive genes. Genetics 37: 189-207.

SAS Institute Inc., 2004. SAS/STAT 9.1 User's Guide, SAS Institute, Cary, North Carolina, USA, Volumes 1-7.

Sedgley M. and Griffin A.R., 1989. Sexual Reproduction of Tree Crops. Academic Press, Sydney.

Shapiro S.S. and Wilk M.B., 1965. An analysis of variance test for normality (complete samples). Biometrika 52: 591-611.

Stram D.O. and Lee J.W., 1994. Variance components testing in the longitudinal mixed effects model. Biometrics 50: 1171-1177.

Vogler D.W. and Kalisz S., 2001. Sex among the flowers: the distribution of plant mating systems. Evolution 55: 202-204.

Volker P.W., 2002. Quantitative Genetics of Eucalyptus globulus, E. nitens and their $\mathrm{F}_{1}$ Hybrid. Unpublished Ph.D. thesis, School of Plant Science, University of Tasmania, Hobart.

Williams C.G. and Savolainen O., 1996. Inbreeding depression in conifers: implications for breeding strategy. For. Sci. 42: 102-117.

Wu H.X., Matheson A.C., and Spencer D., 1998. Inbreeding in Pinus radiata. I. The effect of inbreeding on growth, survival and variance. Theor. Appl. Genet. 97: 1256-1268. 